\title{
To the memory of Robert J. Gorlin
}

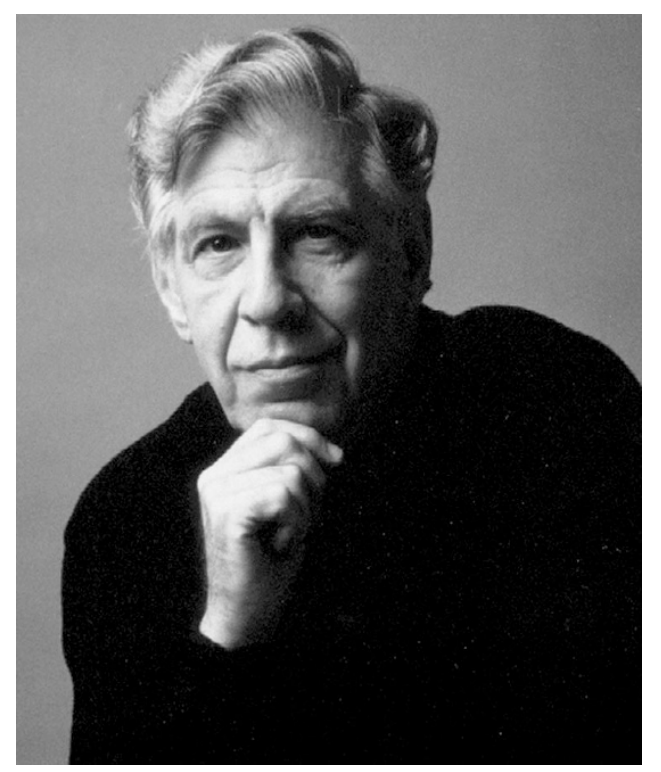

Robert J. Gorlin, MS, DDS

1923-2006

I was very sorry to hear that Professor Robert J. Gorlin, aged 83 years, died on August 29, 2006, in Minneapolis, Minnesota, of lymphoma. He was a pioneer in the fields of genetics, dentistry, surgical pathology, and dermatology.

Dr. Gorlin was born on January 11, 1923, in Hudson, New York. In 1947, he earned his doctor of dental surgery degree at Washington University School of Dentistry and in 1956, his Master's in Oral Pathology from the State University of Iowa. In that same year, he joined the faculty at the University of Minnesota School of Dentistry as associate professor and chair of the Divisions of Oral Histology and Oral Pathology. He became professor emeritus in 1993, although he continued his writing and research until his death.

Dr. Robert Gorlin described more than 100 syndromes involving oral pathology, craniofacial genetics, otolaryngology, and obstetrics. He had more than 700 articles catalogued in PubMed, and he authored several textbooks on genetics and oral pathology. Having begun his career in the pre-genomics era, he nevertheless readily embraced the power of genetics to shed light on clinical syndromes. He was an excellent observer; whereas many clinicians had noted widespread basal cell skin cancer in areas not exposed to sunlight, it was Professor Gorlin who determined that this was a distinct entity sometimes associated with rib deformity, tumors, and eye defects.

Dr. Gorlin was an unbelievably modest, friendly, and enthusiastic individual. At conferences, everyone wished to speak to him and share their cases in hopes of gaining the insight he so frequently provided. He never forgot the physicians he met, or their cases and the syndromes they presented. I am very proud to have known Dr. Robert Gorlin since first meeting him in Athens in 1982.

Dr. Gorlin's work will live on through the syndromes he illuminated and his writings. All of the Turkish geneticists, dentists, pathologists, and plastic surgeons who were so influenced by him will remember him with great affection and respect, as will, I am sure, the rest of the medical world.

Sevim Balci, MD

Department of Clinical Genetics

Hacettepe University Ihsan Dogramaci Children's Hospital

Ankara, Turkey 